\title{
Persistent viral shedding lasting over 60 days in a mild COVID-19 patient with ongoing positive SARS-CoV-2
}

\author{
Lan Zhang ${ }^{1 \#}$, Changbo Li ${ }^{2 \#}$, Yanru Zhou ${ }^{1}$, Binjie Wang ${ }^{2}$, Jiajia Zhang ${ }^{3}$ \\ ${ }^{1}$ MRI Department, the First Affiliated Hospital of Henan University of Chinese Medicine, Zhengzhou 450000, China; ${ }^{2}$ Department of Radiology, \\ Huaihe Hospital of Henan University, Kaifeng 475000, China; ${ }^{3}$ Department of Radiology, Gold Coast University Hospital, Gold Coast 4215, \\ Queensland, Australia \\ \#These authors contributed to equally this study.
}

Correspondence to: Lan Zhang, MD. MRI Department, the First Affiliated Hospital of Henan University of Chinese Medicine, Zhengzhou 450000, China. Email: 13837187787@163.com; Jiajia Zhang, MD. Department of Radiology, Gold Coast University Hospital, 1 Hospital Blvd Southport, Gold Coast 4215, Queensland, Australia. Email: zzjia2008@gmail.com.

Submitted Mar 30, 2020. Accepted for publication Apr 27, 2020.

doi: 10.21037/qims.2020.04.08

View this article at: http://dx.doi.org/10.21037/qims.2020.04.08

A novel coronavirus named a severe acute respiratory syndrome coronavirus 2 (SARS-CoV-2) is sweeping across the entire world rapidly, infecting enormous number of people. Positive real-time reverse transcriptase polymerase chain reaction (RT-PCR) test for SARS-CoV-2 nucleic acid is regarded as the main diagnostic modality for coronavirus disease 2019 (COVID-19) (1). According to the latest Report of the WHO-China Joint Mission on Coronavirus Disease 2019 (COVID-19), the median time from onset to clinical recovery for mild cases is approximately 2 weeks (2). Currently, there is no available data to predict how long positive SARS-CoV-2 detectability can last in the COVID-19 patients following recovery of clinical symptoms. Hereby we report a confirmed COVID-19 patient with only mild clinical symptoms, who has been admitted from January 26 to present (March 27), 2020, at the central hospital of Lankao county, Henan province, China. The patient has been hospitalized for over 60 days due to her ongoing positive SARS-CoV-2 status. Currently she becomes an asymptomatic coronavirus carrier. To our knowledge, this COVID-19 patient has the longest reported positive SARS-CoV-2 status post-treatment, indicating persistent viral shedding. With the ongoing global pandemics, this case highlights the urgency for more epidemiology and virology work to be done to better understand SARS-CoV-2, also the need of being aware of encountering and treating SARS-CoV-2 carrier transformed from COVID-19 patient after treatment. The possibility of chronic SARS-CoV-2 carrier status also puts on a new challenge for current clinical treatment.

A 47-year-old female lives in Wuhan, Hubei Province of China, went back to her hometown (Lankao county, Henan Province) on January 14 for Chinese New Year's family reunion. She began to cough with expectoration, followed by dizziness, headache, nausea and vomiting on January 22. On January 26, she was admitted to the local hospital with low fever $\left[37.5^{\circ} \mathrm{C}\left(99.5^{\circ} \mathrm{F}\right)\right]$, oppressive chest pain and aggravated cough. Her initial laboratory results showed $9.26 \mathrm{mg} / \mathrm{L}$ of C-reactive protein (normal range: $0-5 \mathrm{mg} / \mathrm{L}$ ), $0.1 \%$ of eosinophil ratios (normal range: $0.4-8 \%$ ), $72.5 \%$ of neutrophil ratios (normal range: $40.0-75.0 \%$ ), $21.5 \%$ of lymphocyte ratios (normal range: $20.0-50.0 \%$ ), and throat swab RTPCR test confirmed COVID-19 infection. Her initial chest CT showed bilateral mixed subpleural ground glass opacities (GGO) and consolidation (Figure 1). After 7 days of antiviral treatment and supportive therapy, the patient's temperature returned to normal, and repeated CT on February 3 showed interval improvement of the lung changes (Figure 2). With ongoing treatment, on February 12 (3 weeks after initial onset of symptoms), the patient's respiratory symptoms, including cough, expectoration and chest tightness, had significantly relieved. On corresponding chest CT, the previous bilateral air space changes had also markedly absorbed (Figure 3). The 

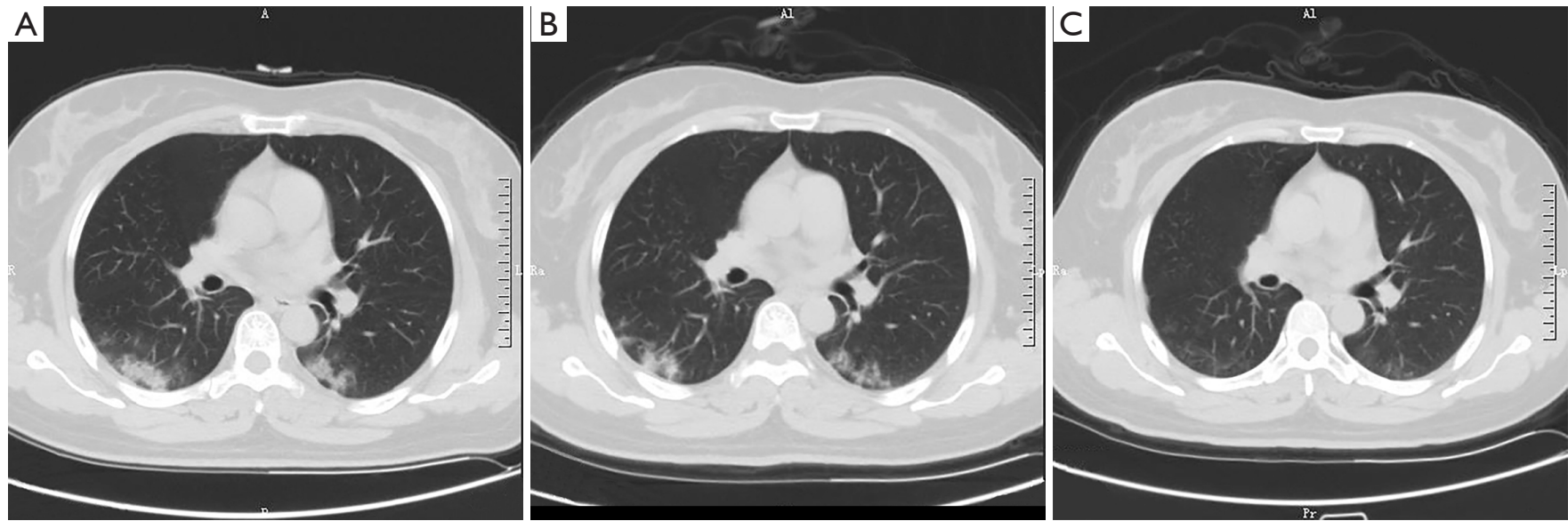

Figure 1 The initial chest CT scan shows bilateral subpleural ground glass opacities (GGO) and consolidation.
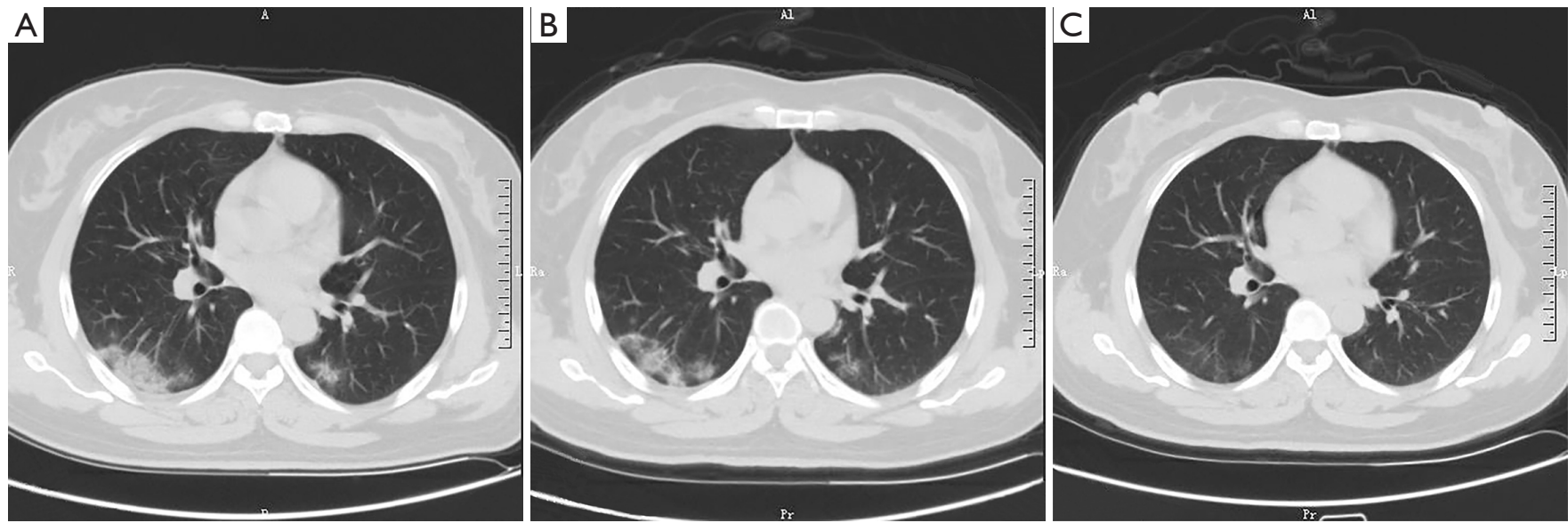

Figure 2 The repeated CT scan on the 8th day after the onset of illness shows partial remission of lung abnormalities.
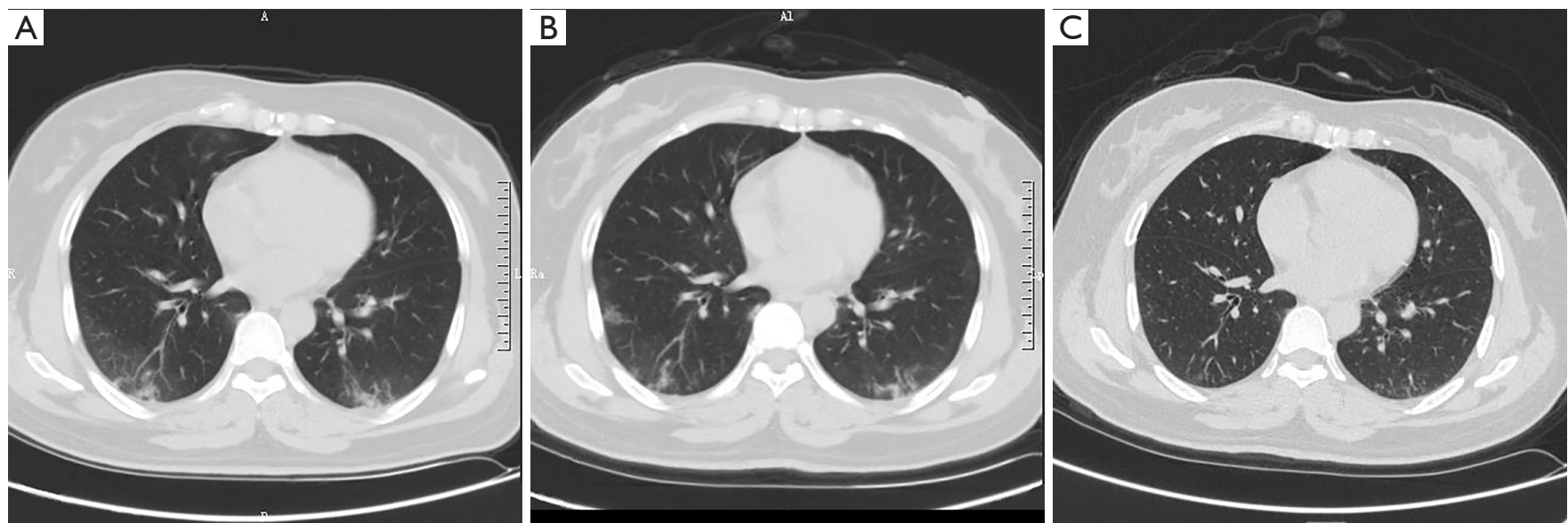

Figure 3 The follow-up CT scan after 18 days of antiviral treatment shows near-complete resolution of the airspace changes in the bilateral lower lobes. 


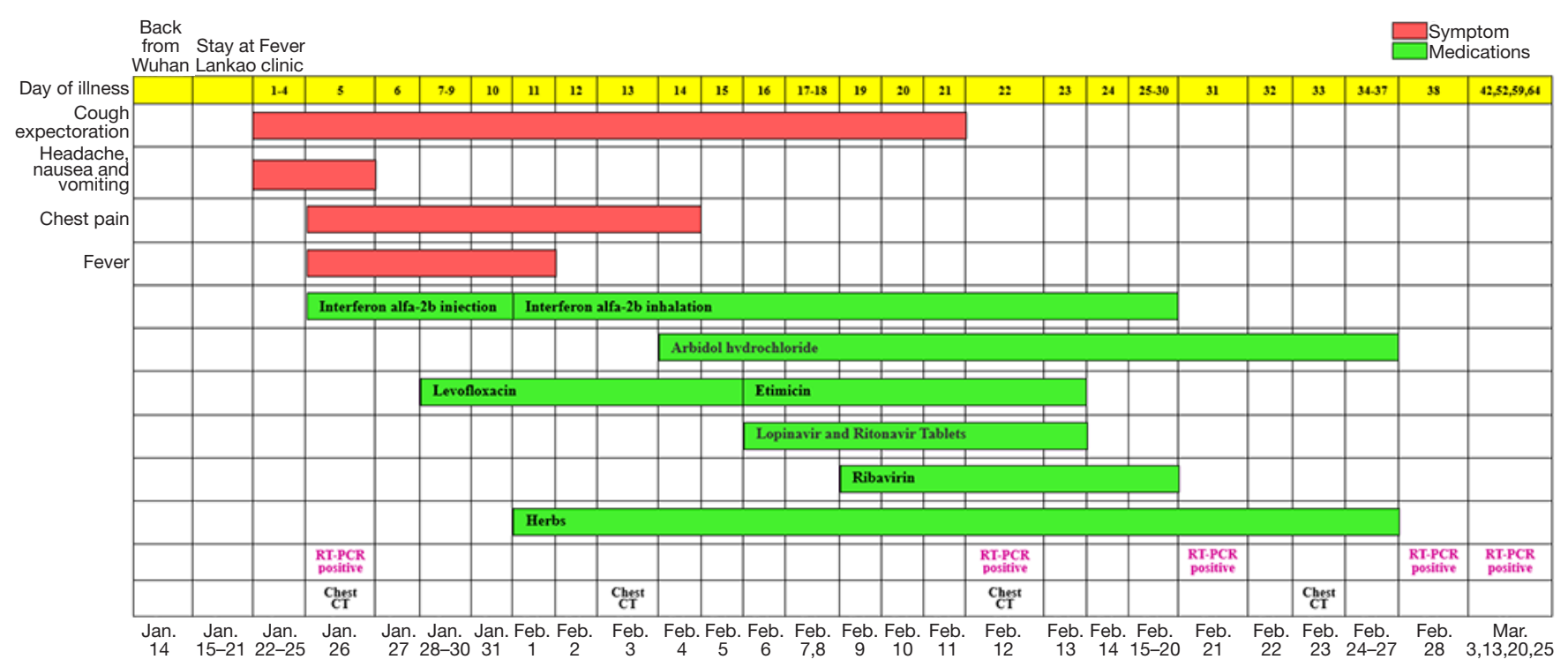

Figure 4 A brief review of patient's clinical course.

second RT-PCR test on the same day however still showed positive result. The third RT-PCR test on February 21 also showed positive. Clinical assessment on February 23 showed no concerning clinical symptoms and chest CT was also clear, and antiviral treatment was stopped. Patient was clinically well, and recommended to practice "Tai Chi" as a rehabilitation therapy. On February 28, the fourth RT-PCR test still showed positive, as a result this patient was not allowed to be discharged, despite all other negative clinical findings. Further repeated RT-PCR tests on March 6, March 13, March 20 and March 25, were still positive. The patient has been isolated in the quarantine ward for 60 days to date (Figure 4).

According to Guidance for Coronavirus Disease 2019 edited by National Health Commission of PRC, all the following criteria should be met for hospital discharge (3): (I) with normal temperature for more than 3 days; (II) with significantly recovered respiratory symptoms; (III) obvious absorption and recovery of acute exudative lesions on chest CT; and (IV) with two negative results of RTPCR test consecutively (sampling interval at least 1 day). After nearly 1 month of active treatment, all the clinical symptoms and radiological abnormalities of the patient had completely resolved, meeting Chinese national criteria (I)(III) for discharge. However, due to her continuous positive SARS-CoV-2 status, the patient is still currently being hospitalized. It has been reported that the median duration of viral shedding for confirmed patients was 20 days from illness onset, with the shortest observed duration of viral shedding among survivors being 8 days, and the longest was 37 days (4). However, the course of the present patient had exceeded 60 days, which is the longest duration to our knowledge. These findings may indicate: (I) the immune system of the patient and SARS-CoV-2 may have reached a state of balanced coexistence, and the patient remains as an asymptomatic virus carrier without any clinical symptoms and imaging manifestations (5), which result in her sustained and ongoing positive RT-PCR test results; (II) there might be a possibility of remarkable delayed elimination of the SARS-CoV-2 even in COVID-19 patients with mild clinical symptoms and who had clinical recovery.

In this report, the patient becomes an asymptomatic SARS-CoV-2 carrier with unremitting viral shedding after treatment. Asymptomatic virus carriers can be still infectious. However, no one can predict how contagious the patient is currently. When the RT-PCR test of this patient will become negative still remains unknown. Environmental test of the patient's ward may be another way to confirm the contagious status according to the recent publication (6).

In conclusion, we present a very rare case of COVID-19 infection with ultra-long SARS-CoV-2 positive status and prolonged post-treatment viral shedding, which warrants more multidisciplinary work to seek further insight into the epidemiology and virology of COVID-19.

\section{Acknowledgments}

Funding: This work was supported by Key project of National Clinical Research Base (2018JDZX042) and the 
Key Research and Development Project of Henan Province of China (202102310087).

\section{Footnote}

Conflicts of Interest: All authors have completed the ICMJE uniform disclosure form (available at http://dx.doi. org/10.21037/qims.2020.04.08). The authors have no conflicts of interest to declare.

Ethical Statement: This study was approved by the local institutional review board. Written informed consent was obtained from the patient for publication of this study and any accompanying images.

Open Access Statement: This is an Open Access article distributed in accordance with the Creative Commons Attribution-NonCommercial-NoDerivs 4.0 International License (CC BY-NC-ND 4.0), which permits the noncommercial replication and distribution of the article with the strict proviso that no changes or edits are made and the original work is properly cited (including links to both the formal publication through the relevant DOI and the license). See: https://creativecommons.org/licenses/by-nc-nd/4.0/.

\section{References}

1. Wang D, Hu B, Hu C, Zhu F, Liu X, Zhang J, Wang B, Xiang H, Cheng Z, Xiong Y, Zhao Y, Li Y, Wang X, Peng Z. Clinical Characteristics of 138 Hospitalized Patients

Cite this article as: Zhang L, Li C, Zhou Y, Wang B, Zhang J. Persistent viral shedding lasting over 60 days in a mild COVID-19 patient with ongoing positive SARS-CoV-2. Quant Imaging Med Surg 2020;10(5):1141-1144. doi: 10.21037/ qims.2020.04.08
With 2019 Novel Coronavirus-Infected Pneumonia in Wuhan, China. JAMA 2020. [Epub ahead of print]. doi: 10.1001/jama.2020.1585.

2. Report of the WHO-China Joint Mission on Coronavirus Disease 2019 (COVID-19). Published on February 1624, 2020. Available online: https://www.who.int/docs/ default-source/coronaviruse/who-china-joint-mission-onCOVID-19-final-report.pdf, accessed on March 10, 2020.

3. China National Health Commission. Diagnosis and treatment of 2019-nCoV pneumonia in China (7th version). In Chinese. Published March 4, 2020. Available online: http://www.nhc.gov.cn/yzygj/s7652m/202003/a3 1191442e29474b98bfed5579d5af95.shtml, accessed on March 10, 2020.

4. Zhou F, Yu T, Du R, Fan G, Liu Y, Liu Z, Xiang J, Wang Y, Song B, Gu X, Guan L, Wei Y, Li H, Wu X, Xu J, Tu S, Zhang Y, Chen H, Cao B. Clinical course and risk factors for mortality of adult inpatients with COVID-19 in Wuhan, China: a retrospective cohort study. Lancet 2020;395:1054-62.

5. Bai Y, Yao L, Wei T, Tian F, Jin DY, Chen L, Wang M. Presumed Asymptomatic Carrier Transmission of COVID-19. JAMA 2020. [Epub ahead of print]. doi: 10.1001/jama.2020.2565.

6. Ong SWX, Tan YK, Chia PY, Lee TH, Ng OT, Wong MSY, Marimuthu K. Air, Surface Environmental, and Personal Protective Equipment Contamination by Severe Acute Respiratory Syndrome Coronavirus 2 (SARSCoV-2) From a Symptomatic Patient. JAMA 2020. [Epub ahead of print]. doi: 10.1001/jama.2020.3227. 